Int. J. Electrochem. Sci., 15 (2020) 2307 - 2325

International Journal of

ELECTROCHEMICAL

SCIENCE

www.electrochemsci.org

\title{
Development of Polymer-based Chemical Sensor to Study the Impact of Polymer Concentration and Freeze-Thaw Cycle on the Detection of Gallic Acid
}

\author{
Sundus Khan and Joo Kheng Goh ${ }^{*}$ \\ School of Science, Monash University Malaysia, Jalan Lagoon Selatan, 47500 Bandar Sunway, \\ Selangor Darul Ehsan, Malaysia. \\ *E-mail: goh.joo.kheng@monash.edu
}

doi: $10.20964 / 2020.03 .40$

Received: 17 September 2019 / Accepted: 25 November 2019 / Published: 10 February 2020

\begin{abstract}
A simple, inexpensive and efficiently sensitive sensor for voltammetric detection of gallic acid (GA) has been fabricated with $0.1 \%$ and $1.0 \% \mathrm{w} / \mathrm{v}$ of polyvinyl alcohol (PVA). Electrode responses were evaluated for the oxidation of 10 to $50 \mu \mathrm{M}$ GA at bare glassy carbon electrode, a GCE modified electrochemically with PVA and PVA/MWCNT/GCE, PVA/ZnO/GCE, PVA/MWCNT/ZnO/GCE composites by solvent casting method. The PVA/GCE at $0.1 \%(\mathrm{w} / \mathrm{v})$ has proven to be the best electrochemical sensor among the four electrochemical modified electrode as it has increased oxidative current to 26 folds as compared to a bare GCE. PVA/GCE $0.1 \%$ (w/v) has detected GA in the lowest concentration range of $50 \mu \mathrm{M}$ with a high sensitivity of $11.03 \pm 1.61 \mu \mathrm{A}$ as compared to bare GCE with $0.43 \mu \mathrm{A}$. The PVA/GCE $0.1 \%$ (w/v) modified chemical sensor has shown more pronounced current sensitivity of $21.85 \pm 1.14 \mu \mathrm{A}$ after 5 freeze-thaw cycles, an effective casting method in this study. Freezethaw cycle method has strengthened PVA hydrogels enhancing the current sensitivity for the detection of GA to 51 folds as compared to bare GCE and 1.98 folds as compared to PVA/GCE (without freezethaw cycle). Satisfactory precision was obtained for PVA/GCE $0.1 \%$ (w/v) (without freeze thaw cycle) with \%RSD of 15.58 whereas, \%RSD for PVA/GCE 0.1\% (w/v) (with 5 freeze-thaw cycle) was 5.24. Under optimal conditions, the polymer based electrochemical sensor PVA/GCE displayed a linear range to GA in the concentration of $1.6 \times 10^{-6}$ to $4.9 \times 10^{-5} \mathrm{~mol} \mathrm{~L}^{-1}$ with a detection limit of $4.95 \times 10^{-7} \mathrm{~mol} \mathrm{~L}$ 1 .
\end{abstract}

Keywords: Electrochemical modified electrode, freeze-thaw cycle, gallic acid, PVA hydrogel, square wave voltammetry

FULL TEXT 
(C) 2020 The Authors. Published by ESG (www.electrochemsci.org). This article is an open access article distributed under the terms and conditions of the Creative Commons Attribution license (http://creativecommons.org/licenses/by/4.0/). 